\title{
A zinc metal-organic framework for concurrent adsorption and detection of uranium
}

Xudong Qin, ${ }^{\mathrm{a}}$ Weiting Yang, ${ }^{\mathrm{a}}$ Y Yonghang Yang, ${ }^{\mathrm{a}}$ Dongxu Gu, ${ }^{\mathrm{a}}$ Dongyu Guo, ${ }^{\text {b }}$ and Qinhe Pan*a

${ }^{a}$ Key Laboratory of Advanced Materials of Tropical Island Resources, Ministry of Education, School of Science, Hainan University, Haikou 570228, China.

${ }^{b}$ Department of Clinical Laboratory, Xiamen Huli Guoyu Clinic, Co., Ltd., Xiamen 361000, China.

*Corresponding author: yangwt@hainanu.edu.cn; panqinhe@163.com; xiamenhaijin@163.com

\section{Contents}

Table S1 Crystal data and structure refinement parameters for HNU-50 ............................................. 2

Table S2 The kinetic parameters for the U(VI) sorption on HNU-50 ................................................... 2

Table S3 Adsorption constants for Langmuir and Freundlich isotherm models ........................................ 2

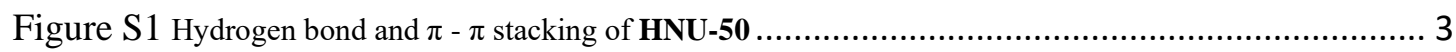

Figure S2 Simulated and experimental powder X-ray diffraction patterns (PXRD) of HNU-50..................... 3

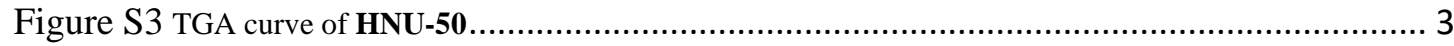

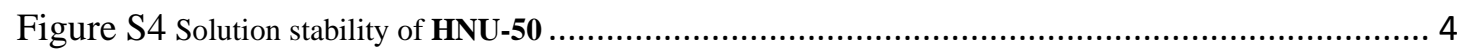

Figure S5 PXRD of simulated, after adsorption and after elution of HNU-50 ......................................... 4

Figure S6 Emission spectra of PMA and HNU-50 ...................................................................... 4

Figure S7 The IR spectra of uranyl nitrate, as-synthesized and U(VI) loaded HNU-50............................... 5

Figure S8 XPS survey spectra of HNU-50 before and after U(VI) adsorption ....................................... 5

Figure S9 Emission spectrum of PMA and absorption spectrum of uranyl nitrate ..................................... 5 
Table S1. Crystal data and structure refinement parameters for HNU-50.

\begin{tabular}{ll}
\hline Crystal data & $\mathrm{HNU}-50$ \\
\hline Empirical formula & $\mathrm{Zn}_{2} \mathrm{C}_{21} \mathrm{~N}_{3} \mathrm{O}_{15} \mathrm{H}_{23}$ \\
Formula weight & 688.20 \\
Crystal system & monoclinic \\
Space group & $C c$ \\
$a(\AA)$ & 16.5622 \\
$b(\AA)$ & 9.4906 \\
$c(\AA)$ & 15.8484 \\
$\alpha\left(^{\circ}\right)$ & 90 \\
$\beta\left(^{\circ}\right)$ & 95.957 \\
$\gamma\left(^{\circ}\right)$ & 90 \\
Volume $\left(\AA^{3}\right)$ & 2477.68 \\
$Z$ & 4 \\
$D$ calcd $\left(\mathrm{g} / \mathrm{cm}^{3}\right)$ & 1.845 \\
$F(000)$ & 1400.0 \\
$\mu$ Mo K $\alpha\left(\mathrm{mm}{ }^{-1}\right)$ & 2.009 \\
Temperature $(\mathrm{K})$ & 150 \\
Range of $h, k, l$ & $20,11,19$ \\
$\theta$ min/max & $5.37 / 74.728$ \\
Reflections collected/unique/ & $0.1021(4844)$ \\
Data/restraints/parameters & $1.95 / 0.98$ \\
$R$ indices $($ all data) & 0.0331 \\
\hline & \\
\hline &
\end{tabular}

Table S2. The kinetic parameters for the U(VI) sorption on HNU-50.

\begin{tabular}{|c|c|c|c|c|c|}
\hline \multicolumn{3}{|c|}{ Pseudo-first kinetics model } & \multicolumn{3}{|c|}{ Pseudo-second kinetics model } \\
\hline$K_{l}\left(\min ^{-1}\right)$ & $q_{e}(\mathrm{mg} / \mathrm{g})$ & $R^{2}$ & $K_{2}\left(\min ^{-1}\right)$ & $q_{e}(\mathrm{mg} / \mathrm{g})$ & $R^{2}$ \\
\hline 0.0083 & 400 & 0.9568 & 2.7627 & 452 & 0.9969 \\
\hline \multicolumn{3}{|c|}{ Langmuir adsorption isotherm } & \multicolumn{3}{|c|}{ Freundlich adsorption isotherm } \\
\hline $\mathrm{Q}_{\mathrm{m}}(\mathrm{mg} / \mathrm{g})$ & $\mathrm{k}_{\mathrm{l}}(\mathrm{L} / \mathrm{mg})$ & $\mathrm{R}^{2}$ & $\mathrm{k}_{\mathrm{f}}(\mathrm{mg} / \mathrm{g})$ & $\mathrm{n}$ & $\mathrm{R}^{2}$ \\
\hline 632 & 0.265 & 0.9983 & 126 & 0.9708 & 0.9139 \\
\hline
\end{tabular}




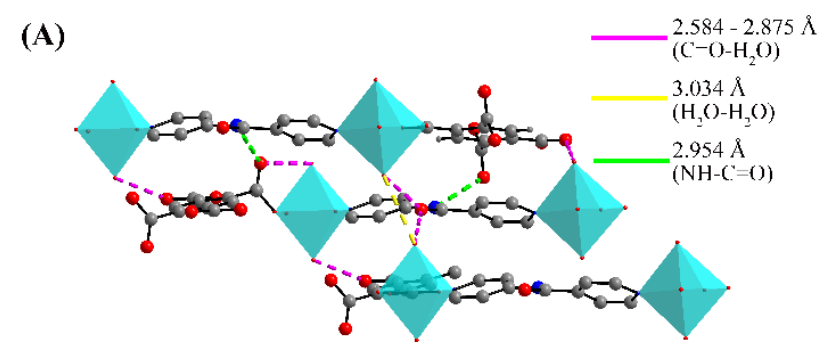

(B)

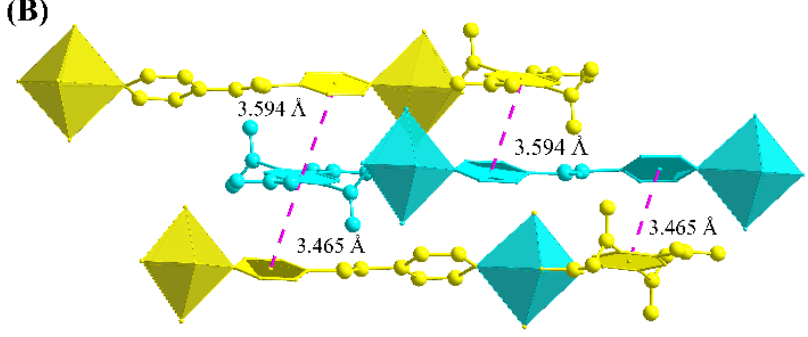

Figure S1. (A) Schematic diagram of H-bond between two-dimensional layers of HNU-50; (B) Diagram of $\pi-\pi$ stacking between two layers of HNU-50.

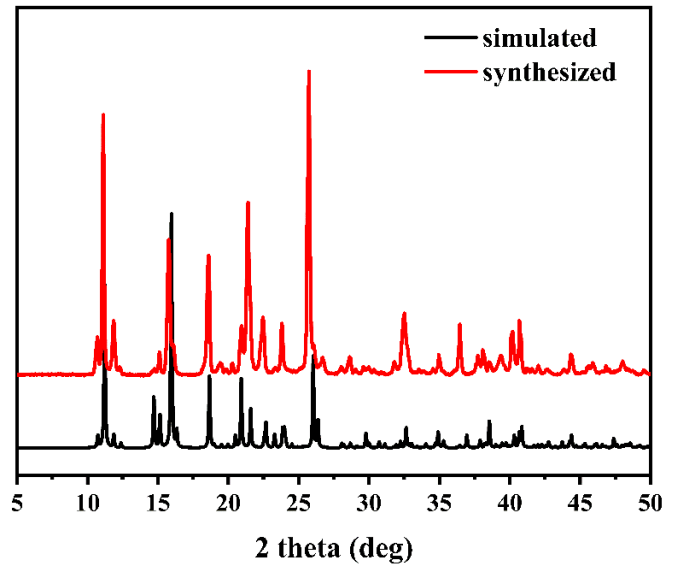

Figure S2. Simulated and experimental powder X-ray diffraction patterns (PXRD) of HNU-50.

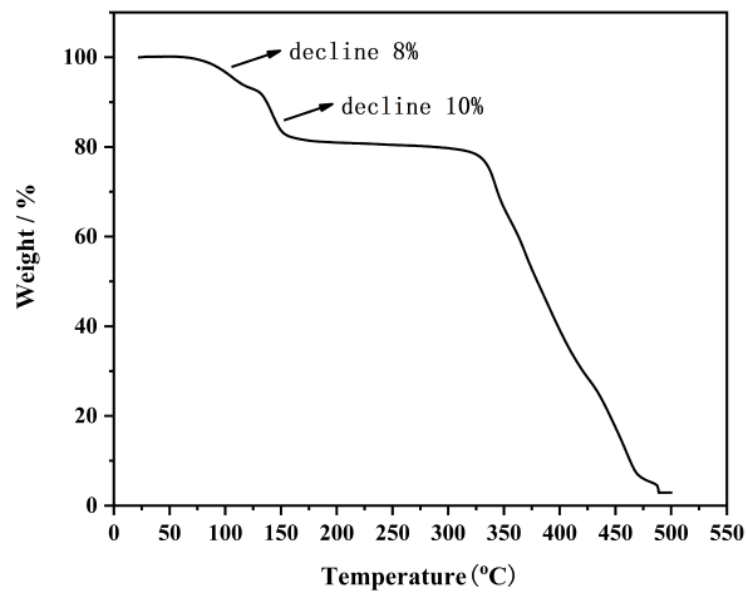

Figure S3. TGA curve of HNU-50. 


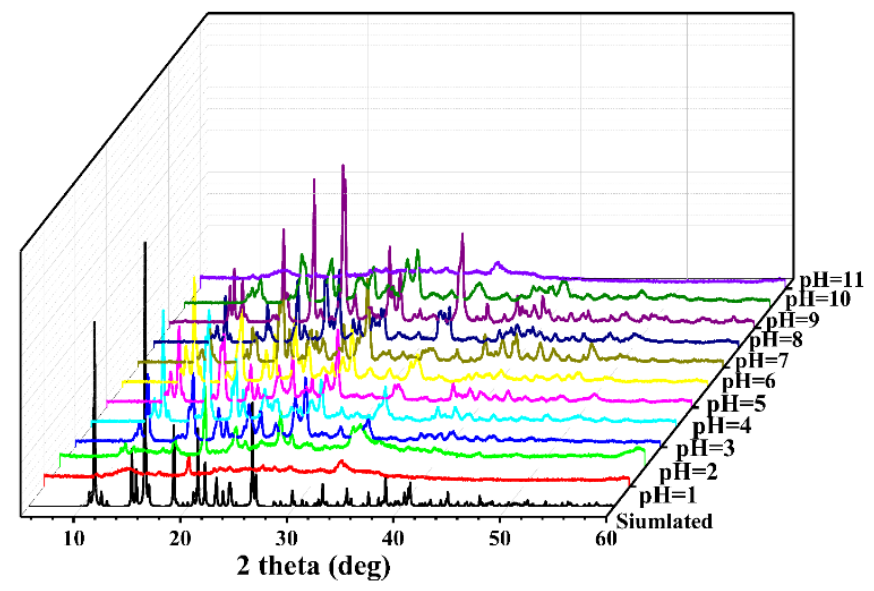

Figure S4. PXRD of HNU-50 in aqueous solution with different $\mathrm{pH}$ for 12 hours.

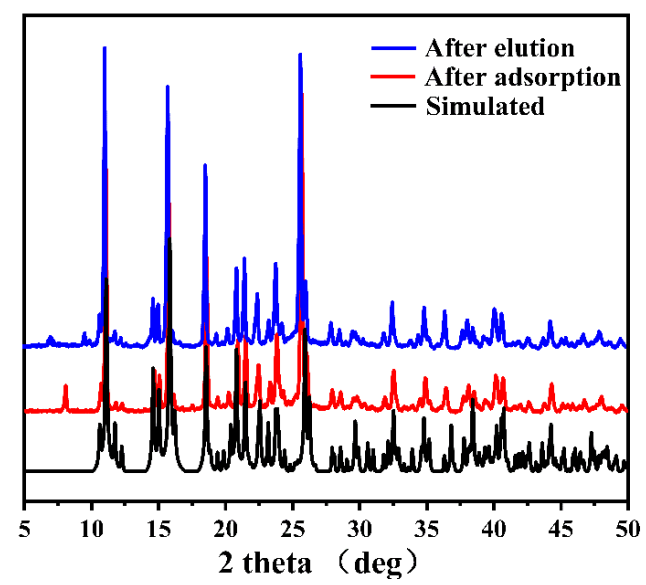

Figure S5. PXRD of simulated, after adsorption and after elution of HNU-50.

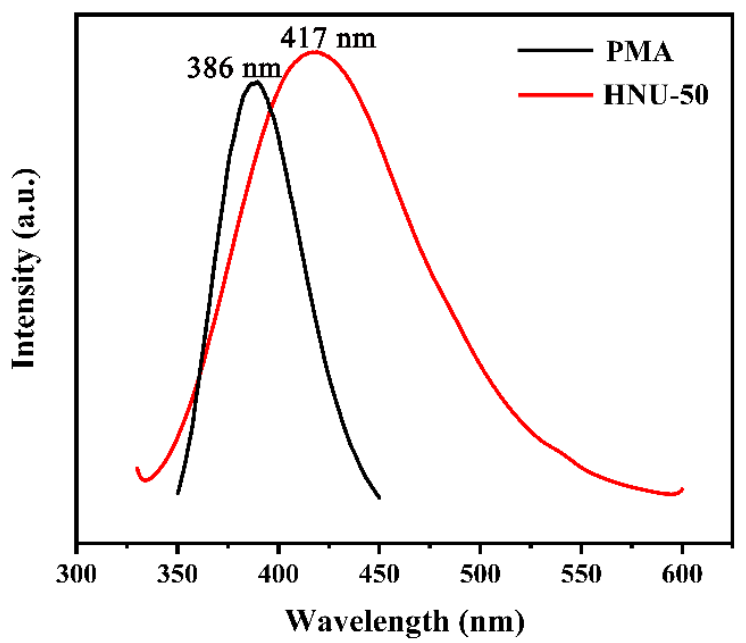

Figure S6. Emission spectra of PMA (black, $\lambda_{\mathrm{ex}}=345 \mathrm{~nm}$ ) and HNU-50 (red, $\lambda_{\mathrm{ex}}=312 \mathrm{~nm}$ ). 


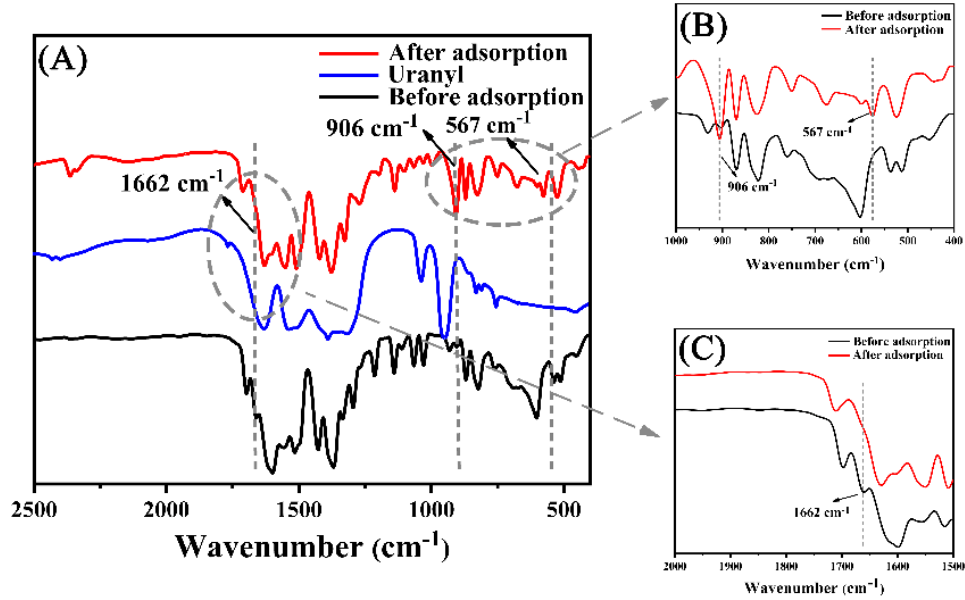

Figure S7. The IR spectra of uranyl nitrate, as-synthesized and U(VI) loaded HNU-50.

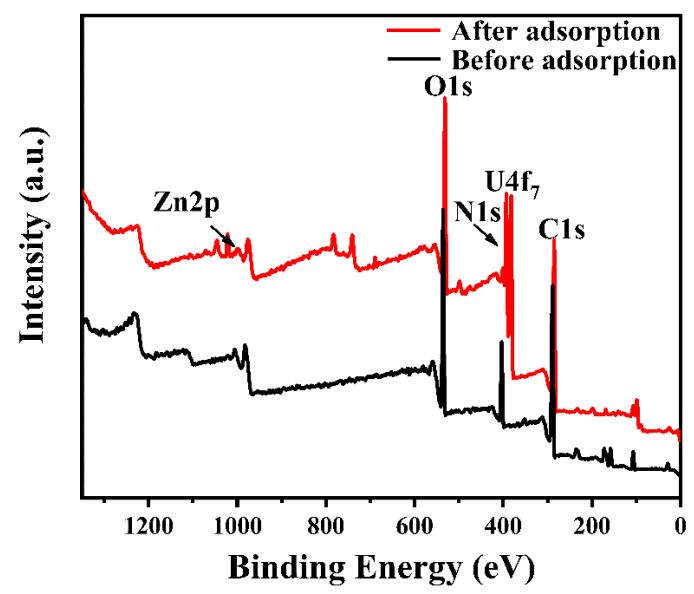

Figure S8. XPS survey spectra of HNU-50 before and after U(VI) adsorption.

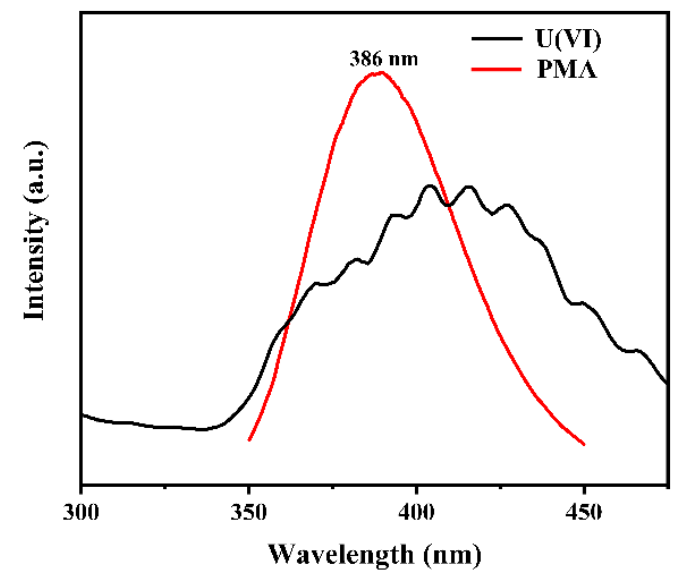

Figure S9. Emission spectrum of PMA (red, $\lambda_{\mathrm{ex}}=345 \mathrm{~nm}$ ) and absorption spectrum of uranyl nitrate (black, $\lambda_{\mathrm{em}}=$ $513 \mathrm{~nm})$. 